Library Acquisitions: Practice \& Theory, 1997, Vol. 21, Issue 3, p. 260-262.

ISSN: 0364-6408

http://www.sciencedirect.com/

http://www.sciencedirect.com/science/article/pii/S0364640897000537

http://dx.doi.org/10.1016/S0364-6408(97)00053-7

(C) 1997 Elsevier B.V. All rights reserved.

\title{
Money Talks, But Can It Listen? The Journals Faculty Say They Read: A Report
}

\section{Carol Pitts Diedrichs}

Robin Lent, Louise Buckley, and David Lane, all from the University of New Hampshire (UNH), discussed the project they developed to answer the question of what faculty say they read. The library had already been through three major cancellation projects. Lent indicated that they had never had a "fat period" from which to shrink; things had always been lean, making it difficult to find things to cancel in order to add new items. Serials already consumed $80 \%$ of the materials budget.

In 1995, they decided to try a new approach of asking the faculty what they actually read. The speakers had a goal of a 100\% return rate on the survey so they started by pre-testing the survey on library staff. Once the problems identified in the pre-test were resolved, they sent the survey to 600 faculty members. They also sent a letter to the faculty liaisons in each academic department to solicit their help in getting the surveys completed and returned. In addition, they pursued each individual faculty member in order to get a response to each survey. Despite these efforts, the library determined that a $50 \%$ return rate would result in enough information to be meaningful. They actually achieved a return rate of $51 \%$

The survey included a cover letter of instructions. The faculty were asked to list all of the journals that they read including any personal subscriptions. They were not given a list to chose from, in hopes that a more meaningful answer of what was really read would be achieved. The survey included several specific questions, such as how much of each issue was read, what was the purpose of the reading, i.e., research or teaching, and whether they made any contribution to the journals, such as serving on the editorial board, writing reviews, etc. Some general questions relating to library services involving journals were also included.

As the survey results began to come in, the speakers determined that they had really asked too much. As a result, they created a database of titles reported, faculty member's name and department, subscribing department, and cost of title if not already on subscription. They also tabulated the responses to the general questions. Their preliminary findings include:

- 2,098 unique titles were listed;

- 1,593 were on subscription by UNH (76\% of titles listed);

- 349 were not on subscription by UNH (17\% of titles listed); and

- 156 titles were unverifiable (7\% of titles listed).

One of the major questions remaining from these preliminary findings was what should be done about the approximately 4,400 titles (from a total of 6,000) that were not mentioned by a single faculty member? Lent indicated that they decided to investigate what a reasonable number of titles on subscription would be for an institution of their size. They looked at peer institutions; 
only two had fewer titles than UNH and those had 5,000 fewer students. Lent completed her portion of the presentation with the following conclusions related to collection development:

- They acquired a greater knowledge of their periodical collection.

- This was a feasible method of engaging the faculty.

- The process allowed them to link individual titles to individual faculty.

- Looking at titles by college may be more useful than by department.

- A core list of journals may be unique to each institution.

- Document delivery is not the whole answer.

- $\$ 60,000$ would fill the identified unmet need.

David Lane's presentation addressed the in-depth study of one department within the larger project, Animal and Nutritional Sciences. The chair of the department sent a letter to faculty saying that they had better complete the survey because the library was going to cancel everything that was not mentioned. This department had an $82 \%$ response rate and included 132 unique titles. Lane indicated that the core list theory was not borne out by this portion of the study. In theory, a core list is expected to be less than the number of titles already subscribed to. In the case of Animal and Nutritional Sciences, no title was read by everyone in the department. Since journal use data for the past 10 years are available for the titles in this area, that data as well as the ISI Journal Citation Reports and the survey results will be built into the database for future tracking.

The third and final speaker was Louise Buckley, who addressed the issues of interdisciplinary studies. She reviewed and evaluated the titles listed that were on current subscription for their interdisciplinary use across departments. Cancellation should not occur just based on information from the department level or titles that are of use to other departments will be canceled. Buckley also discussed in more depth the general questions included on the survey:

- How do they keep up with the journal literature in the field?

- How do they get an article if it is not on subscription?

- What was their use of electronic journals?

- What interest did they have in specific journal services, such as online full text, tables of contents, expressed article delivery, etc.?

- What interest did they have in using acquisitions dollars to subsidize new services in lieu of new or current journal subscriptions?

Buckley was not able to include detailed responses to all of these question because of time constraints with the program. However, she indicated that Interlibrary Loan was the most common way that the faculty obtained access to journals not on subscription, followed by asking a colleague or using another library. When asked about their interest in using acquisitions dollars for services, $43 \%$ were in favor of this approach, $43 \%$ were opposed, and $12 \%$ did not know.

The program concluded with a discussion of what the authors planned to do with these findings. They plan to discuss the results with the faculty and bibliographers. A letter will be sent to the university administration on the need for additional funds (for the titles identified but not on subscription). They will develop a policy on periodical collection development. They plan to extend the survey to other user groups and update the lists from each faculty member. They also plan to develop the "world's largest serials database" including their use data, pricing information, and the survey results. 